\title{
Pengaruh Impulsivitas dan Media Komunikasi terhadap Perbedaan Partisipasi Diskusi Online
}

\author{
Irma Suhartini ${ }^{1}$ E, Fathul Himam ${ }^{2}$ \\ Fakultas Psikologi Universitas Gadjah Mada
}

\begin{abstract}
This study aimed to determine the effect of impulsivity and computer-mediated communication on differences in online participation. This research was an experimental research with posttest only design. Participants involved in this study were students with an age range of 17-22 years, totaling 30 participants. Participants were divided into two groups namely using the computer-mediated communication real name (CMR) and computermediated communication anonymously (CMA), each group consisted of 15 participants. This study used Barrat Impulsive Scale (BIS) 11 to determine participants' impulsivity. Data analysis in this study used two-way analysis of variance (two-way ANOVA). Based on the result of the interaction model analysis between impulsivity and computer-mediated communication to online participation, it is known that the value of $F=1.587$ with significance equal to $0.219(p>0,05)$. This research found that there was no significant difference in online participation based on computer-mediated communication of CMR and CMA, both at low, medium and high levels of impulsivity.
\end{abstract}

Keywords: computer-mediated communication; impulsivity; online participation

Abstrak. Penelitian ini bertujuan untuk mengetahui pengaruh impulsivitas dan media komunikasi terhadap perbedaan partisipasi online. Penelitian ini merupakan penelitian eksperimen dengan desain posttest only design. Partisipan yang terlibat dalam penelitian ini adalah mahasiswa dengan rentang usia 17 - 22 tahun yang berjumlah 30 partisipan. Partisipan akan dibagi menjadi dua kelompok yaitu yang menggunakan media komunikasi dengan nama asli (computer-mediated communication real name-CMR) dan yang anonim (computer-mediated communication anonymously-CMA), masing-masing kelompok terdiri dari 15 partisipan. Penelitian ini menggunakan Barrat Impulsive Scale (BIS) 11 untuk mengetahui Impulsivitas partisipan. Analisis data pada penelitian ini menggunakan twoway analysis of variance (ANAVA dua jalur). Berdasarkan hasil analisis model interaksi antara impulsivitas dan media komunikasi terhadap partisipasi online diketahui bahwa nilai $F=1,587$ dengan signifikansi sebesar $0,219(p>0,05)$. Hasil penelitian ini menemukan bahwa tidak ada perbedaan partisipasi online yang signifikan berdasarkan media komunikasi CMR dan CMA, baik pada tingkat impulsivitas yang rendah, sedang, maupun tinggi.

Kata kunci: impulsivitas; media komunikasi; partisipasi online

Era digital memberikan pengaruh besar bagi kehidupan individu melalui hampir seluruh

${ }^{1}$ Korespondensi dapat dilakukan melalui

1irma.suhartini@mail.ugm.ac.id

2 Atau melalui fhimam@ugm.ac.id aktivitas yang melibatkan teknologi termasuk komunikasi dengan menggunakan internet. Perkembangan Teknologi, Informasi, dan Komunikasi (TIK) tersebut memberikan pengaruh terhadap proses pembelajaran dalam 
pendidikan, dengan adanya e-learning. Elearning merupakan perangkat elektronik dan digital yang mendukung pembelajaran dan pengajaran (Whitty \& Young, 2017).

Pembelajaran online merupakan bentuk lingkungan belajar yang difasilitasi oleh e-learning (Whitty \& Young, 2017). Pembelajaran online atau distance education (pendidikan jarak jauh) merupakan sistem pembelajaran yang sepenuhnya memberikan fasilitas belajar secara online. Perkembangannya yang cepat membuat semakin banyak Perguruan Tinggi yang menyediakan fasilitas pembelajaran seperti ini, karena pembelajaran dapat terjadi kapan pun dan dimana pun tanpa batas waktu dan tempat serta dapat melibatkan siapa saja (Bender, 2003).

Selain itu, terdapat pula sistem pembelajaran yang dapat dilakukan mahasiswa tidak hanya belajar secara online akan tetapi, juga pada waktu tertentu dapat melakukan tatap muka secara langsung. Proses belajar seperti ini disebut dengan Blended atau Hybrid Learning (Bender, 2003). Keuntungankeuntungan yang dapat dirasakan dari Hybrid learning diantaranya, pembelajaran di kelas yang pada umumnya terbatas oleh waktu, tetapi dapat dilanjutkan melalui diskusi online. Selain itu, metode belajar yang berbeda akan lebih mengakomodasi pembelajaran agar lebih efektif, seperti siswa yang kurang aktif saat dikelas, melalui diskusi online dapat lebih aktif dan berani untuk berpartisipasi (Bender, 2003).

Akan tetapi, saat diskusi berlangsung siswa tidak hanya mengalami pengalaman positif seperti memahami pembelajaran lebih mendalam, mengaplikasikan pembelajaran, dan meningkatkan kemampuan bekerja di dalam tim (Clinton \& Kelly, 2017). Para peserta juga mengalami pengalaman yang negatif terhadap diskusi, seperti adanya peserta yang mendominasi atau pasif, peserta yang bersikap bijaksana atau kekanak-kanakkan, dan peserta yang mau bekerja keras atau yang menghindar untuk bekerja sama (Hillyard, Gillespie \& Littig, 2010). Hal ini menggambarkan bahwa terdapat perbedaan tingkat partisipasi pada diskusi. Adanya kemungkinan perbedaan partisipasi dalam diskusi bertatap muka juga berpeluang terhadap adanya perbedaan partisipasi saat diskusi online.

Partisipasi online merupakan bagian dari aktivitas diskusi online. Partisipasi online dibagi kedalam beberapa tingkatan (Hrastinski, 2008) yaitu: partisipasi berdasarkan banyaknya mengakses pembelajaran online, partisipasi berdasarkan kuantitas tulisan, partisipasi berdasarkan kualitas tulisan, partisipasi berdasarkan tulisan dan bacaan, partisipasi berdasarkan jumlah tulisan yang penting, serta partisipasi berdasarkan ikut serta dan bergabung dalam dialog.

Terdapat beberapa faktor yang menjadi pendorong dan penghalang dalam partisipasi online. Faktor yang dapat mendorong partisipasi online diantaranya seperti: 1) kesempatan untuk meningkatkan pengetahuan dan kemampuan, 2) fokus kepada topik yang menarik, 3) kepedulian diri (selfawareness), 4) dukungan teman sebaya, 5) kesempatan untuk bertukar ide-ide, 6) dukungan dan pengawasan dari dosen, 7) kesempatan untuk mengenal mahasiswa dari program studi lain, 8) memperoleh dukungan untuk menyelesaikan tugastugas, 9) mengembangkan kepercayaan diri, dan 10) aplikasi dan desain yang bagus (Daud, Khalid, Ahmad, Rahman \& Karim, 2016). 
Sebaliknya, terdapat pula faktor yang menghalangi partisipasi online, seperti: 1) tidak familiar dengan program aplikasi, 2) lemahnya koneksi internet, 3) keterbatasan waktu, 4) kurang percaya diri, 5) keterikatan yang kurang antara satu sama lain, 6) topik yang kurang menarik, 7) tidak ada notifikasi dari program aplikasi, dan 8) terlalu banyak postingan (Daud, et al., 2016). Selain itu, partisipasi dalam diskusi dapat terhalang ketika peserta tidak suka untuk bekerja bersama dengan peserta lain. Ketidaksukaan tersebut dapat disebabkan oleh adanya pembahasan di luar topik saat diskusi sehingga cenderung tidak produktif (Clinton \& Kelly, 2017).

Hal ini, dapat memungkinkan bervariasinya partisipasi dalam diskusi online. Adanya perbedaan individual (individual differences) menjadi salah satu kecenderungan bervariasinya partisipasi online tersebut, yang dapat dipengaruhi oleh gaya belajar dan berpikir. Gaya belajar dan berpikir tersebut diantaranya seperti refleksivitas dan impulsivitas (Santrock, 2014). Penelitian ini ingin mencari tahu lebih lanjut mengenai gaya belajar dan berpikir yang impulsivitas.

Impulsivitas merupakan perilaku yang cenderung muncul secara spontan dan tiba-tiba tanpa refleksi terhadap apa yang sedang terjadi (Bagana \& Raciu, 2012). Barratt mengidentifikasi tiga komponen impulsif antara lain: (1) perhatian yaitu ketidakmampuan individu untuk memusatkan perhatian, (2) motorik merupakan kecenderungan untuk bertindak pada kendali saat itu, dan (3) tidak terencana yaitu kecenderungan untuk tidak berpikir teliti dan merencanakan masa depan (Patton, Stanford, \& Barratt, 1995).

Karakter impulsivitas yang cenderung spontan tersebut berpeluang terhadap banyaknya ide-ide yang disampaikan saat diskusi online berlangsung. Akan tetapi, terdapat kemungkinan bahwa partisipasi yang terjadi tidak seperti yang diharapkan, karena karakter impulsivitas yang spontan dapat dengan mudah mengalihkan topik pembahasan atau cepat merespon percakapan yang tidak sesuai dengan topik pembahasan diskusi. Hal ini, diperkuat bahwa karakter impulsivitas diketahui memiliki keterbatasan terhadap kinerja seperti ketelitian (Tzagarakis, Pellizzer, \& Rogers, 2013). Adanya karakter ini, memungkinkan untuk memunculkan partisipasi diskusi online yang bervariasi.

Diskusi online melalui media komunikasi CMC dapat dilakukan dengan menggunakan nama asli (Computermediated real name, CMR) dan tanpa nama (Computer-mediated anonymous, CMA). Computer-mediated communication memberikan keuntungan seperti ide-ide lebih banyak disampaikan saat diskusi terutama pada kelompok peserta tanpa nama atau anonim (CMA) dibandingkan kelompok yang diskusi melalui FTF dan CMR (Adrianson \& Hjelmquist, 1999). Ideide yang lebih banyak ini dikarenakan saat diskusi identitas peserta tidak saling diketahui sehingga cenderung lebih aktif selama proses diskusi. Diskusi melalui CMA akan membantu bagi individu yang memiliki ekstroversi rendah.

Perilaku yang muncul saat identitas yang tidak diketahui atau anonim dalam menggunakan media komunikasi masih menjadi perhatian para peneliti. Teori online disinhibition effect yang dikemukakan oleh Suler mengatakan bahwa pada kondisi anonim individu menunjukkan perilaku yang lebih beresiko yang pada umumnya tidak terlihat saat bertatap muka atau di dunia 
nyata karena adanya perasaan tidak diawasi (Blau \& Caspi, 2010). Perasaan tidak diawasi ini dapat memperkuat individu untuk menuliskan percakapan yang tidak relevan dan ejekan yang dapat memberikan perasaan tidak nyaman pada lawan bicara (Adrianson \& Hjelmquist, 1999; Blau \& Caspi, 2010).

Anonimitas juga dapat memberikan efek positif seperti adanya perasaan keleluasan pribadi (privacy) terhadap kesejahteraan psikologis (Christopherson, 2007). Individu dapat tetap menjaga identitas pribadinya dari hal-hal yang tidak diinginkan seperti digunakan oleh pihak lain yang tidak bertanggung jawab saat menggunakan media komunikasi. Christopherson (2007) menambahkan bahwa anonimitas dapat menguntungkan bagi kesejahteraan psikologis individu sebagai fungsi untuk pemulihan, katarsis, dan otonomi dalam hal kemampuan untuk mengekspresikan diri yang dapat berpengaruh terhadap kesehatan. Adanya kecenderungan-kecenderungan perilaku yang terlihat pada karakter impulsivitas dan kondisi anonim tersebut, berkemungkinan untuk memengaruhi partisipasi online. Sehingga penelitian ini berhipotesis bahwa impulsivitas dan media komunikasi berpengaruh terhadap perbedaan partisipasi diskusi online.

\section{Metode}

\section{Partisipan penelitian}

Partisipan dari penelitian ini merupakan mahasiswa Universitas Gadjah Mada yang berjumlah 30 partisipan dengan rentang usia 17 - 22 tahun. Partisipan yang bersedia untuk bergabung dalam penelitian ini kemudian ditempatkan secara acak pada media komunikasi yang telah ditentukan.
Desain dan prosedur

Penelitian ini merupakan penelitian kuantitatif yang menggunakan pendekatan eksperimen dengan penempatan subjek secara acak yang disebut dengan Randomized Experiment (Shadish, Cook, \& Campbell, 2002) melalui undian terhadap media komunikasi yang akan digunakan partisipan. Desain yang digunakan dalam penelitian ini adalah posttest only design.

Partisipan akan ditempatkan di dalam ruangan yang sama dengan dibatasi partisi sehingga partisipan tidak dapat melihat satu sama lain. Pada tiap ruang yang dibatasi partisi terdapat meja, kursi, laptop, dan map. Map tersebut berisi lembar penjelasan, informed consent, skala impulsivitas, petunjuk diskusi, lembar jawaban, selembar kertas kosong, dan pulpen.

Anggota kelompok diskusi masingmasing terdiri dari lima partisipan (dapat dilihat pada Tabel 1). Eksperimen dimulai dengan meminta partisipan membaca lembar penjelasan, kemudian mengisi informed consent dan skala impulsivitas. Setelah fasilitator memastikan seluruh peserta telah mengisi kedua lembar tersebut, partisipan diarahkan untuk membaca petunjuk diskusi.

Tiap partisipan akan diskusi secara online melalui situs http://chatzy.com, dan akan dimulai setelah mendapat arahan dari fasilitator mengenai keseluruhan aturan dalam eksperimen termasuk hanya dibenarkan mengakses situs tersebut selama eksperimen berlangsung. Partisipan yang berdiskusi dengan media CMR akan diminta untuk mengetikkan nama asli, sedangkan partisipan yang menggunakan media CMA menuliskan Anggota_1, Anggota_2, Anggota_3, Anggota_4, atau Anggota_5 sesuai dengan keterangan map yang diperoleh. 
Tabel 1.

Distribusi Partisipan berdasarkan Media Komunikasi pada Kasus Social Dilemma

\begin{tabular}{cccc}
\hline \multirow{2}{*}{ Kasus } & \multicolumn{2}{c}{ Media Komunikasi } & \multirow{2}{*}{ Total kelompok } \\
\cline { 2 - 3 } & CMR & CMA & 2 \\
\multirow{3}{*}{ Social Dilemma } & Kelompok 1 & Kelompok 4 & 2 \\
& Kelompok 2 & Kelompok 5 & 2 \\
\hline Total kelompok & Kelompok 3 & Kelompok 6 & 6 \\
\hline
\end{tabular}

Keterangan: Setiap kelompok diskusi terdiri dari 5 partisipan

Tabel 2.

Distribusi Hadiah untuk Kasus Social Dilemma

\begin{tabular}{ccc}
\hline $\begin{array}{c}\text { Jumlah yang memilih } \\
\text { untuk Kerja sama }\end{array}$ & $\begin{array}{c}\text { Hadiah untuk yang } \\
\text { Mangkir }(\mathrm{M})\end{array}$ & $\begin{array}{c}\text { Hadiah untuk yang Kerja } \\
\text { sama (K) }\end{array}$ \\
\hline 5 & - & 40.000 \\
4 & 50.000 & 30.000 \\
3 & 40.000 & 20.000 \\
2 & 30.000 & 10.000 \\
1 & 20.000 & 0 \\
0 & 10.000 & - \\
\hline
\end{tabular}

Kelompok diskusi yang telah dibagi menggunakan media CMR dan CMA tersebut untuk selanjutnya akan diminta membahas permasalahan kasus Social dilemma. Diskusi Social dilemma, dimulai dengan memberikan petunjuk permainan kepada partisipan oleh fasilitator yang berisi tabel jumlah hadiah. Partisipan diminta untuk mendiskusikan apakah akan memilih Kerjasama (K) atau Mangkir (M) dengan mempertimbangkan hadiah yang akan diperoleh saat memutuskan akan kerjasama atau mangkir.

Saat partisipan membaca petunjuk, fasilitator membacakan cara bermain dan menanyakan berapa jumlah hadiah yang akan diperoleh ketika anggota kelompok dalam jumlah tertentu memilih untuk kerjasama atau mangkir. Fasilitator menjelaskan cara bermain dengan mencontohkan petunjuk permainan seperti yang terlihat pada Tabel 2, misalnya jika hasil voting terdapat 4 orang yang memilih "Kerjasama" (K) dan satu orang memilih "Mangkir" (M).

Empat orang yang memilih "Kerjasama" masing-masing akan mendapatkan Rp 30.000,-, sedangkan 1 orang yang memilih "Mangkir" akan mendapatkan Rp 50.000,-.

Permainan tidak akan dimulai hingga seluruh partisipan dalam kelompok telah sepenuhnya memahami prinsip-prinsip permainan. Permainan ini tidak memiliki batas waktu, akan tetapi rata-rata berlangsung selama satu jam tiga puluh menit (Adrianson \& Hjelmquist, 1999). Ketika selesai membaca petunjuk, partisipan dapat memulai diskusi melalui situs chatting yang telah diakses dan melakukan komunikasi secara tertulis dengan mengetikkan obrolan (chatting) yang kemudian akan disimpan dalam sistem, sambil fasilitator mengingatkan bahwa partisipan tidak diizinkan untuk berkomunikasi secara lisan. Tiap anggota 
kelompok bebas untuk mendiskusikan apa pun yang diinginkan tentang permainan, di antaranya mengenai strategi, dan poin hadiah. Saat tiap partisipan siap dengan pilihan masingmasing, partisipan diminta untuk menuliskan pilihannya yaitu memilih untuk Kerjasama (K) atau Mangkir (M) pada lembar jawaban. Partisipan tidak diizinkan untuk menunjukkan pilihan yang ditulis pada anggota lain di kelompoknya, yang artinya partisipan diskusi dapat saja memilih untuk bekerjasama, akan tetapi pada kenyataannya memilih mangkir.

Hal ini dikarenakan ada jaminan dari fasilitator untuk tidak memberitahu siapapun mengenai strategi partisipan dalam bermain, sehingga terdapat kemungkinan partisipan akan "menipu" satu sama lain. Kertas yang berisi pilihan masing-masing partisipan tersebut kemudian dikumpulkan. Fasilitator mengumumkan hasilnya secara lisan, mengatakan kepada kelompok mengenai hasilnya, misalnya "Permainan ronde pertama memiliki tiga orang yang memilih bekerja sama dan dua orang yang memilih mangkir", artinya tiga orang yang memilih bekerja sama masing-masing akan mendapat hadiah 20.000,- dan dua orang yang memilih mangkir masingmasing akan mendapatkan hadiah 40.000,. Setelah hasil tersebut diumumkan, diskusi ronde kedua dimulai. Saat kelompok telah memutuskan tindakan berikutnya untuk kerjasama atau mangkir, lalu mengumpulkan jawaban, dan kemudian fasilitator mengumumkan hasilnya. Prosedur yang sama diulangi sebanyak lima ronde hingga kelompok selesai melakukan diskusi.
Cara pengumpulan data

Partisipan yang telah mendaftar dan bersedia bergabung pada penelitian ini kemudian ditempatkan secara acak dalam menentukan tipe media komunikasi apa yang akan digunakan. Penempatan partisipan akan dibagi ke dalam enam kelompok diskusi, dan tiap kelompok diskusi terdiri dari 5 partisipan. Tiga kelompok diskusi ditempatkan pada salah satu dari dua jenis media yaitu, pada media Computer-mediated communication real name (CMR) atau menggunakan nama asli terdiri dari 15 partisipan, dan pada media Computer-mediated communication anonymously (CMA) atau anonim yang juga terdiri dari 15 partisipan. Tipe kasus yang akan dibahas oleh partisipan adalah kasus Social dilemma. Diskusi dilakukan dengan menggunakan komputer melalui situs percakapan http://chatzy.com. Hasil diskusi yang diperoleh akan tersimpan di dalam sistem dan selanjutnya akan dihitung serta dijumlahkan kata bermakna yang diperoleh setelah diskusi berlangsung.

Penelitian ini menggunakan Skala Barratt Impulsive Scale (BIS) 11 untuk mengetahui impulsivitas partisipan (Patton, Stanford, \& Barratt, 1995). Skala BIS 11 terdiri dari 30 aitem dengan tiga aspek, yaitu perhatian, motorik, dan tidak terencana. Pada tiap aitem partipisan diminta untuk memilih satu dari empat pilihan yaitu: $1=$ Tidak Pernah, $2=$ Kadangkadang, 3= Sering, dan 4= Selalu. Skor 4 menunjukkan respon yang paling impulsif. Semakin tinggi total skor impulsivitas yang diperoleh maka semakin tinggi tingkat impulsivitas, sedangkan semakin rendah total skor yang diperoleh maka semakin rendah tingkat impulsivitas. 
Tabel 3.

Deskripsi Data

\begin{tabular}{ccccccccc}
\hline \multirow{2}{*}{ Variabel } & \multicolumn{4}{c}{ Hipotetik } & \multicolumn{5}{c}{ Empirik } \\
\cline { 2 - 9 } & $\mathrm{X}_{\min }$ & $\mathrm{X}_{\text {maks }}$ & Rerata & SD & $\mathrm{X}_{\min }$ & $\mathrm{X}_{\text {maks }}$ & Rerata & SD \\
\hline $\begin{array}{c}\text { Partisipasi } \\
\text { Online }\end{array}$ & - & - & - & - & 31 & 193 & 100,67 & 45,23 \\
Impulsivitas & 20 & 80 & 50 & 10 & 36 & 55 & 45,9 & 5,10 \\
\hline
\end{tabular}

Tabel 4.

Deskripsi Impulsivitas dan Media Komunikasi terhadap Perbedaan Partisipasi Online Berdasarkan Jumlah Kata Bermakna

\begin{tabular}{ccccc}
\hline $\begin{array}{c}\text { Media } \\
\text { Komunikasi }\end{array}$ & $\begin{array}{c}\text { Kategorisasi } \\
\text { Impulsivitas }\end{array}$ & $\begin{array}{c}\text { Rerata Jurmlah Kata } \\
\text { Bermakna }\end{array}$ & SD & $\mathrm{N}$ \\
\hline \multirow{3}{*}{ CMR } & Rendah & 118,00 & & 1 \\
& Sedang & 100,93 & \multirow{2}{*}{43,947} & 14 \\
& Total & 102,07 & & 15 \\
\hline \multirow{3}{*}{ CMA } & Rendah & 57,67 & & 3 \\
& Sedang & 109,67 & 47,983 & 15 \\
& Total & 99,27 & & \\
\hline
\end{tabular}

Skala BIS 11 cukup banyak impulsivitas adalah 50, sedangkan nilai digunakan dan diadaptasi oleh beberapa deviasi standar (SD) dari skala negara diantaranya Arab Saudi (Ellouze, impulsivitas adalah 10. Data empirik Ghaffari, Zouari, Zouari, \& M'rad, 2013), Partisipasi online, diketahui bahwa skor Cina (Yao et al., 2007), dan Jepang (Someya terendah adalah 31 sedangkan skor et al., 2001) dengan reliabilitas antara 0,78 tertinggi adalah 193. Nilai rerata dari sampai 0,80. Pada penelitian ini, peneliti Partisipasi online adalah 100,67 dan nilai menggunakan skala BIS 11 yang telah deviasi standarnya adalah 45,23. Pada data diadaptasi dan digunakan pada subjek empirik skala Impulsivitas diperoleh skor penelitian di Indonesia ( $\mathrm{N}=240)$ dengan terendah adalah 36 dan skor tertinggi nilai Cronbach's Alpha 0,82 (Adrianson, adalah 55. Nilai rerata skala impulsivitas Ancok, Ramdhani, \& Acher, 2013). adalah 45,9 dan deviasi standarnya adalah 5,10 .

Analisis data

Analisis data pada penelitian ini menggunakan Two-way analysis of varience.

\section{Hasil}

Pada Tabel 3 terlihat bahwa skor terendah skala impulsivitas adalah 20, skor tertinggi adalah 80 , nilai rerata hipotetik dari skala

Berdasarkan perbandingan data hipotetik dan empirik tersebut menunjukkan bahwa tingkat Impulsivitas mahasiswa cenderung lebih rendah, karena rerata data empirik lebih rendah dibandingkan data hipotetik. Berdasarkan uji coba pada 60 orang partisipan diperoleh nilai Cronbach Alpha skala impulsivitas sebesar 0,837 . 
Tabel 4 menunjukkan bahwa media

Tabel 5.

Hasil analisis impulsivitas dan media komunikasi terhadap perbedaan partisipasi online

\begin{tabular}{lcc}
\hline \multicolumn{1}{c}{ Model } & F & Sig. \\
\hline Media Komunikasi & 0,886 & 0,355 \\
Kategori Impulsivitas & 0,406 & 0,530 \\
Media Komunikasi ${ }^{*}$ Kategori Impulsivitas & 1,587 & 0,219 \\
\hline
\end{tabular}

Sepuluh aitem gugur setelah dilakukan pengujian sehingga jumlah aitem skala impulsivitas pada penelitian ini berkurang dari 30 aitem menjadi 20 aitem.

Pada penelitian ini, dapat diketahui bahwa rerata partisipasi online berdasarkan kategorisasi impulsivitas dan media komunikasi, seperti yang terlihat pada Tabel 4. Rerata partisipasi online berdasar-kan jumlah kata bermakna pada media komunikasi CMR dengan kategori impulsivitas rendah adalah 118, dan merupakan rerata partisipasi online tertinggi pada media komunikasi CMR. Selanjutnya, rerata partisipasi online pada media komunikasi CMR dengan kategori impulsivitas sedang sebesar 100,93. Tingkat partisipasi online pada media komunikasi CMR tergolong sedang dengan rerata total 102,07.

Rerata partisipasi online berdasarkan jumlah kata bermakna pada media komunikasi CMA dengan kategori impulsivitas rendah adalah 57,67, pada kategori impulsivitas sedang adalah 109,67 dan merupakan partisipasi online tertinggi pada media komunikasi CMA. Tingkat partisipasi online pada media komunikasi CMA juga tergolong sedang dengan rerata total 99,27. Partisipasi online berdasarkan media komunikasi pada komunikasi CMR menunjukkan rerata partisipasi online tertinggi yaitu 118 . Walaupun, baik antara media komunikasi CMR dan CMA tidak memiliki perbedaan rerata yang terlalu jauh.

Berdasarkan uji hipotesis diketahui hasil analisis seperti yang terlihat pada Tabel 5. Tabel 5 memperlihatkan bahwa nilai $\mathrm{F}$ media komunikasi adalah 0,886 dengan signifikansi sebesar 0,355 ( $p>0,05)$, sehingga diketahui bahwa tidak terdapatperbedaan partisipasi online yang signifikan antara media komunikasi CMR dan CMA. Pada kategori impulsivitas, diketahui nilai $\mathrm{F}$ sebesar 0,406 dengan signifikansi $0,530 \quad(p>0,05) \quad$ yang menunjukkan bahwa tidak terdapat perbedaan partisipasi online yang signifikan berdasarkan impulsivitas.

Nilai F pada interaksi antara media komunikasi dan impulsivitas diketahui sebesar 1,587 dengan signifikansi 0,219 ( $>00,05)$, dan disimpulkan bahwa tidak terdapat perbedaan partisipasi online melalui interaksi antara media komunikasi dan impulsivitas. Dengan demikian, berdasarkan hasil analisis dengan menggunakan Two-way analysis of variance disimpulkan bahwa hipotesis penelitian yang menyatakan impulsivitas dan media komunikasi berperan terhadap perbedaan partisipasi online ditolak. 


\section{Pembahasan}

Tujuan dari penelitian ini adalah untuk mengetahui pengaruh impulsivitas dan media komunikasi terhadap perbedaan partisipasi online. Berdasarkan hasil penelitian ini, tidak ada perbedaan partisipasi online yang signifikan berdasarkan interaksi antara media komunikasi baik CMR dan CMA, pada kategori impulsivitas yang rendah, sedang, maupun tinggi. Kemungkinan impulsivitas dan media komunikasi tidak terbukti terhadap adanya perbedaan partisipasi online dikarenakan rerata impulsivitas pada penelitian ini tergolong rendah, serta tidak terdapat partisipan yang termasuk ke dalam kelompok impulsivitas tinggi, sehingga kurang mampu melihat keterlibatan impulsivitas secara menyeluruh.

Impulsivitas dan reflektivitas dapat bersama-sama dalam menentukan perilaku individu. Menurut teori reflectiveimpulsive model (RIM) yang dikemukakan oleh Strack dan Deutsch (2012), sistem reflektif dapat berlangsung ketika kapasitas kognitif dan pengetahuan tersedia, untuk selanjutnya bertanggung jawab meregenarasi dan mentransformasi pengetahuan tersebut sehingga memunculkan inferensi-inferensi terhadap apa yang akan dilakukan. Kondisi ini menjadi informasi yang mendasari dalam pengambilan keputusan yang dapat dipengaruhi oleh akses seleksi informasi pada sistem impulsif. Sistem impulsif dipengaruhi oleh mekanisme yang memfasilitasi pendekatan dan pengelakan (approach dan avoidance). Perilaku mendekat akan muncul ketika adanya pengalaman dan perasaan yang positif, sedangkan perilaku mengelak akan muncul ketika adanya pengalaman dan perasaan yang negatif.
Impulsivitas jika muncul pada saat yang tepat akan memiliki fungsional. Dickman (1990) membedakan impulsivitas berdasarkan fungsional dan disfungsional. Impulsivitas disfungsional dapat terjadi saat merespon sesuatu dengan cepat dan tidak optimal. Sebaliknya, impulsivitas fungsional dapat terjadi ketika respon yang diberikan tepat dan adaptif. Dickman (1990) melanjutkan bahwa membedakan impulsivitas menjadi dua tipe merupakan sesuatu hal yang penting untuk memahami peran dari fungsi adaptif.

Penelitian longitudinal selama delapan tahun yang dilakukan oleh Valiente et al. (2013) ditemukan bahwa tingkat impulsivitas sedang terbukti secara signifikan berhubungan positif terhadap pencapaian, yaitu semakin tinggi impulsivitas akan semakin tinggi pula pencapaian dengan mengontrol effortful control. Effortful control merupakan kemampuan yang berfungsi eksekutif untuk mengendalikan perhatian dan perilaku dari hal-hal yang dapat mengganggu fokus atau sesuatu yang menjadi distraktor saat menyelesaikan tugas-tugas tertentu (Valiente et al., 2013).

Berdasarkan pemaparan sebelumnya, dapat disimpulkan bahwa impulsivitas tidak selalu memunculkan perilaku yang berefek negatif. Impulsivitas dapat memberikan keuntungan ketika terlibat dalam proses reflektivitas, berada pada kondisi yang fungsional dan tepat, serta didukung oleh adanya kemampuan kontrol perhatian dan perilaku yang baik. Hal ini, dapat menjadi gambaran bahwa tidak adanya perbedaan partisipasi online kemungkinan karena partisipan pada penelitian ini melibatkan kondisi-kondisi tersebut saat eksperimen berlangsung. 
Selain itu, tidak adanya perbedaan yang signifikan pada tingkat partisipasi online yang diketahui melalui jumlah kata bermakna antara media CMR dan CMA sejalan dengan apa yang ditemukan oleh Ainsworth et al. (2011), bahwa tidak terdapat perbedaan jumlah kata pada individu yang berpartisipasi secara anonim dan yang diketahui oleh publik.

Kemungkinan tidak adanya perbedaan partisipasi online berdasarkan media komunikasi baik CMR ataupun CMA dikarenakan jenis kasus yang digunakan untuk diskusi pada penelitian ini, yaitu kasus social dilemma. Pemecahan masalah berdasarkan kasus ini dapat membatasi pemberian informasiinformasi oleh partisipan saat diskusi karena hanya terbatas untuk memilih kerjasama atau mangkir.

Hal ini memunculkan kondisi dilema bagi partisipan karena partisipan yang memilih mangkir akan mendapatkan hadiah yang lebih besar dan akan menguntungkan diri sendiri, tetapi disisi lain ketika memilih untuk kerjasama justru akan mengurangi hadiah yang akan diterima. Kondisi dilema ini cenderung akan memunculkan strategi permainan yang timbal-balik (Kerr \& Park, 2001) yang membuat peserta diskusi hanya membahas hal yang sama secara berulangulang. Kemungkinan lainnya adalah dikarenakan kondisi anonim saat diskusi. Kondisi-kondisi anonim akan memberikan pengaruh yang tepat ketika berada pada konteks yang tepat, seperti saat membahas isu-isu yang sensitif kondisi anonim pada computer-mediated communication dapat memfasilitasi partisipan dalam berdiskusi (Mcleod, 2011).

\section{Kesimpulan}

Penelitian ini menemukan bahwa tidak ada perbedaan partisipasi online yang signifikan berdasarkan interaksi antara media komunikasi baik CMR maupun CMA, dengan memperhatikan impulsivitas partisipan penelitian. Hal ini kemungkinan dikarenakan impulsivitas tidak selalu memunculkan perilaku yang berefek negatif. Impulsivitas dapat memberikan keuntungan ketika terlibat dalam proses reflektivitas, berada pada kondisi yang fungsional dan tepat, serta didukung oleh adanya kemampuan kontrol perhatian dan perilaku yang baik. Selain itu, kemungkinan lainnya adalah dikarenakan kondisi anonim saat diskusi. Kondisi-kondisi anonim akan memberikan pengaruh yang tepat ketika berada pada konteks yang tepat, seperti saat membahas isu-isu yang sensitif kondisi anonim pada computer-mediated communication dapat memfasilitasi partisipan dalam berdiskusi.

\section{Saran}

Berdasarkan hasil penelitian ini, peneliti memberikan saran bagi peneliti selanjutnya di antaranya, dapat mempertimbangkan untuk melakukan screening terhadap skor impulsivitas sebelum melibatkan partisipan pada penelitian agar sebaran tingkat impulsivitas merata, dan dapat mempertimbangkan jenis kasus yang akan digunakan dengan melibatkan ahli bahasa agar kasus yang akan digunakan dapat memunculkan respon yang lebih bervariasi antar peserta diskusi. Selain itu, dapat mempertimbangkan kelompok partisipan yang berbeda seperti yang berasal dari berbagai macam profesi atau tingkatan pendidikan tertentu. 


\section{Daftar Pustaka}

Adrianson, L., Ancok, D., Ramdhani, N., \& Acher, T. (2013). Cultural influences upon health, affect, self-esteem and impulsiveness: An IndonesianSwedish comparison. International Journal of Research Studies in Psychology, 2(3), 25-44. doi: 10.5861/ijisp.2013.228.

Adrianson, L., \& Hjelmquist, E. (1999). Group processes in solving two problems: Face-to-face and computer-mediated communication. Behaviour \& Information Technology, 18(3), 179-198. doi: 10.1080/014492 $\underline{999119075}$

Ainsworth, S., Gelmini-hornsby, G., Threapleton, K., Crook, C., Malley, C. O., \& Buda, M. (2011). Anonymity in classroom voting and debating. Learning and Instruction, 21, 365-378. doi: $\quad$ 10.1016/j.learninstruc.2010. $\underline{05.001}$

Bagana, E., \& Raciu, A. (2012). Anxiety, impulsiveness and time perception among secondary and high school students. Procedia - Social and Behavioral Sciences, 33, 890-894. 10.1016/j.sbspro.2012.01.250

Bender, T. (2003). Discussion-based online teaching to enhance student learning: Theory, practice, and assessment. Virginia: Stylus Publishing.

Blau, I., \& Caspi, A. (2010). Studying invisibly: media naturalness and learning. Proceedings of The Chais Conference on Instructional Technologies Research 2008: Learning in the Technological Era. doi: 10.1007/978-14419-6139-6.

Christopherson, K. M. (2007). The positive and negative implications of anonymity in internet social interactions: "On the internet, nobody knows you're a dog." Computers in Human Behavior, 23, 3038-3056. doi: 10.1016/j.chb.2006. 09.001.

Clinton, V., \& Kelly, A. E. (2017). Student attitudes toward group discussions. Active Learning in Higher Education, 111. doi: $10.1177 / 1469787417740277$.

Daud, M. Y., Khalid, F., Ahmad, M., Rahman, M. J. A., \& Karim, A. A. (2016). "To participate or not?": Identifying the factors affecting university students' participation in an e-forum. Creative Education, 7, 2791-2802. doi: 10.4236/ce.2016. 718259.

Dickman, S. J. (1990). Functional and dysfunctional impulsivity: Personality and cognitive correlates. Journal of Personality and Social Psychology, 58(1), 95-102. 10.1037/0022-3514.58.1.95.

Ellouze, F., Ghaffari, O., Zouari, O., Zouari, B., \& M'rad, M. F. (2013). Measurement: BIS 11 - Dialectical Arabic version. Diunduh dari http://www.impulsivity.org/measure ment/bis11 Arabic

Hillyard, C., Gillespie, D., \& Littig, P. (2010). University students' attitudes about learning in small groups after frequent participation. Active Learning in Higher Education, 11(1), 920. doi: $10.1177 / 1469787409355867$.

Hrastinski, S. (2008). What is online learner participation? A literature review. Computers \& Education, 51, 1755-1765. doi: 10.1016/j.compedu.2008.05.005.

Kerr, N. L., \& Park, E. S. (2001). Group performance in collaborative and social dilemma tasks: Progress and prospects. Dalam Hogg, M. A \& Tindale, S (Eds.) Blackwell handbook of social psychology: Group Processes. Massachusetts: Blackwell Publishers 
Mcleod, P. L. (2011). Effects of anonymity and social comparison of rewards on group brainstorming. Small Group Research, 42(4), 475-503. doi: 10.1177/1046496410397381.

Patton, J. H., Stanford, M. S., \& Barratt, E. S. (1995). Factor structure of the barratt impulsiveness scale. Journal of Clinical Psychology, 51(6), 768-774.

Santrock, J. W. (2014). Psikologi pendidikan (edisi kelima, buku 1). Penerjemah: Bimasena, H. Jakarta: Salemba Humanika.

Shadish, W. R., Cook, T. D., \& Campbell, D. T. (2002). Experimental and quasiexperimental designs for generalized casual inference. Boston: Houghton Miffin.

Someya, T., Sakado, K., Seki, T., Kojima, M., Reist, C., Tang, S. W., \& Takahashi, S. (2001). Measurement: BIS 11 - Japanese version. Diunduh dari http://www.impulsivity.org/measure ment/bis11 japanese

Strack, F., \& Deutsch, R. (2012). A theory of impulse and reflection. Dalam Handbook of theories of social psychology, volume 1. Editor: Van lange, Kruglanski, \& Higgins. London: Sage. Tzagarakis, C., Pellizzer, G., \& Rogers, R. D. (2013). Impulsivity modulates performance under response uncertainty in a reaching task. Exp Brain Res, 225, 227-235. doi: 10.1007/s00221-012-3363-6.

Valiente, C., Eisenberg, N., Spinrad, T. L., Haugen, R., Thompson, M. S., \& Kupfer, A. (2013). Effortful control and impulsivity as concurrent and longitudinal predictors of academic achievement. The Journal of Early Adolescence, 33(7), 946-972. doi: 10.1177/0272431613477239.

Whitty, M. T, \& Young, G. (2017). Cyberpsychology: The study of individuals, society and digital technologies. UK: Wiley.

Yao, S., Yang, H., Zhu, X., Auerbach, R. P., Abela, J. R., Pulleyblank, R. W., \& Tong, X. (2007). Measurement: BIS 11 Chinese version. Diunduh dari http://www.impulsivity.org/measure ment/bis11 Chinese 